\begin{tabular}{|l|l|l||}
\hline \multicolumn{2}{|c|}{ PublisherInfo } \\
\hline \hline PublisherName & $:$ & BioMed Central \\
\hline \hline PublisherLocation & $:$ & London \\
\hline \hline PublisherImprintName & $:$ & BioMed Central \\
\hline \hline
\end{tabular}

\title{
Earlier palliative care in ITU nonsurvivors
}

\begin{tabular}{|l|l|l||}
\hline \multicolumn{2}{|c||}{ ArticleInfo } \\
\hline \hline ArticleID & $:$ & 4299 \\
\hline \hline ArticleDOI & $:$ & $10.1186 /$ ccf-2001-73201 \\
\hline \hline ArticleCitationID & $:$ & 73201 \\
\hline \hline ArticleSequenceNumber & $:$ & 10 \\
\hline \hline ArticleCategory & $:$ & Paper Report \\
\hline \hline ArticleFirstPage & $:$ & 1 \\
\hline \hline ArticleLastPage & $:$ & 3 \\
\hline \hline & & RegistrationDate : 2001-12-3 \\
ArticleHistory & $:$ & Received \\
\hline ArticleCopyright & $:$ 2001-3-16 \\
\hline \hline ArticleGrants & $:$ & OnlineDate \\
\hline \hline ArticleContext & $:$ & 1305455 \\
\hline \hline
\end{tabular}


Malcolm Watters, ${ }^{\text {Affl }}$

Aff1 Princess Margaret Hospital, Swindon

\section{Keywords}

Illness scoring, ICU, outcome

\section{Context}

Patients who stay for long periods in the ITU and ultimately don't survive comprise $13 \%$ of the total but account for $32 \%$ of resources. It is inhumane to continue ITU therapies when there is no hope of survival. By having regular discussions with patient, relatives, and the critical care team, can the ITU resources used by patients who ultimately die be reduced?

\section{Significant findings}

Median ITU stay reduced from 4 to 3 days. This corresponds to 200 fewer days for every 100 patients. Analysis of subgroups showed that this reduction was in the targeted group, ie the patients with higher APACHE scores who died. The intervention did not increase overall mortality. The result is that dying patients spend less time in the ITU.

\section{Comments}

Patients who spend a long time in the ITU and do not survive use a huge amount of ITU resources, as well as suffering lengthy and sometimes painful interventions; identifying these patients early and offering palliative rather than aggressive critical care may be both more humane and conserve ITU resources. These goals are laudable but difficult to achieve. The decision to withdraw treatment is often delayed by both staff and relatives in order to offer the patient 'one more chance'. This study is difficult to read but concludes that if goals and expectations are discussed with patients and relatives (eg weaning to continuous positive airway pressure within a certain time) and these milestones are not achieved then palliative care should be discussed. The result was that palliative care was started earlier without affecting overall unit mortality. The inference is that patients who were expected to survive were not compromised by this intervention. The paper does not mention how difficult the goals were to acheive 
for the patient, and, of course, it is difficult to identify patients who were set unrealistic goals, and therefore, for whom palliative care was discussed inappropriately.

\section{Methods}

Prospective, non-blinded change of practice intervention. Within $72 \mathrm{~h}$ of admission anyone with a predicted length of stay of $>5$ days (from APACHE 3 data) entered the study. 'Clinical milestones' were agreed between the family and ITU team as to what constituted success and failure of treatment. If patients met milestones, new ones were set, and if not, alternatives, including palliative care, were discussed. The team also met to ensure consistency in patients plan.

\section{Additional information}

\section{References}

1. Lilly CM, De Meo DL, Sonna LA, Haley KJ, Massaro AF, Wallace RF, Cody S: An intensive communication intervention for the critically ill. Am J Med. 2001, 109: 469-475. 